\title{
Teaching as a Disciplined Act: A Grounded Theory
}

\author{
Seyyed Ali Ostovar-Namaghi \\ Shahrood University of Technology, Iran \\ Email: saostovarnamaghi@yahoo.com
}

\begin{abstract}
This study aimed to explore why language teaching in public high schools in Iran is so shallow and disconnected from scholarship. Interview data were collected and analysed through the grounded theory procedures. Iterative data collection and analysis yielded teaching as a disciplined act as the core category. Teachers do as they are told because binding directives and circulars specify a set of permissible acts. This set of acts is then naturalised as good practice through teaching teams, evaluation scheme and promotion criteria. Disciplined practice entails deskilling since teachers don't find a chance to use their professional knowledge and skills.
\end{abstract}

Index Terms - disciplined act, grounded theory, disciplinary power, deskilling

\section{INTRODUCTION}

The heyday of methods can be considered to have lasted until the late 1980s. Classes were observed to evaluate the degree to which teaching and learning activities were in line with a specific method. As Richards and Rodgers (2001) cogently state, good teaching was regarded as correct use of the method and its prescribed principles and techniques. Since good practice was defined as the degree of conformity with a given method, scholars of language teaching were on the lookout for the best method for three decades. But this endeavour proved futile. Along this line, Yalden (1987, p.17), contends, "despite discussion and experimentation for more than three decades, the language teaching profession has reached no conclusion as to which method is intrinsically best."

Disappointment with the 'method' concept led scholars of language teaching to rethink and focus on an alternative to methods. Following Dewey (1933) and Schon (1983) scholars of language teaching defined good practice as one that is reflective. That is, rather than prescribing a pre-fabricated procedure which involves an ordered progression from 'approach' to 'method' to teaching 'techniques' (Anthony, 1963), educators thought that language teaching profession would be better grounded if teachers were trusted to improve their practice through reflection. The notion that teachers should be reflective practitioners became widely accepted in teacher education circles in the 1980s and 1990s (Brookfield, 1995).

With its ever increasing acceptance in the educational circle reflective practice is now a paradigm that dominates teacher education around the world (Lee, 2007). Pre-service teacher education, in particular, has shifted its emphasis from a transmission-oriented to a constructivist approach, where teacher learners focus on what they know instead of what they do, bringing prior knowledge and personal experience to bear on the new learning situations (Cochran-Smith \& Lytle, 2001). As such the syllabus requirement for reflective practice encourages greater self-reliance through questioning and reflection, and is suggestive of a socially-constructed view of learning that recognizes teaching as an essentially complex, interactive, and contingent activity (Brandt, 2008).

This paradigm shift was taken to be very promising for language teacher education. Following Schon's conception of teaching, Richards (1991) argued that bottom-up approaches, especially those based on teacher self-reflection, hold the most promise for developing effective teachers because they emphasise development, discovery, and inquiry rather than training in fixed methodologies. Similarly, Richards and Lockhart (1994) argued that reflective practice could better serve the profession than making teachers conform to an external model.

Thus from the early 1940s to date, scholars have been preaching two dominant conceptions of good teaching. From the heydays of the Audiolingual to the late 1980s, they defined good practice as conformity with a given method. From the early 1990s to date, good practice has been defined as being reflective in nature. Whereas in the methods era teachers were prescribed to ascribe to a certain method, they are now prescribed to improve their practice through reflection. This, however, is a difficult process, since it 'requires critical thought, self-direction, and problem solving coupled with personal knowledge and self-awareness' (Chant, Heafner, \& Bennett, 2004, p. 25).

Moreover, reflection is contingent upon teachers' working conditions. "Under appropriate conditions self-reflection in reflective practice is a process of self-enhancement" (Yip, 2006, p.783). However, under inappropriate conditions such as oppressive and demanding teaching environments this conception of teaching loses its colour. Under such conditions, teachers' actions are directed by the particularities and exigencies of the society for which teachers teach rather than by their personal theories generated through reflection. In some contexts such as public high schools in Iran, observation of teachers' work indicates that the glorious rhetoric of teaching profession has yielded dismal practice in action since 
language teaching is often shallow, simplistic, and disconnected from authentic scholarship. Scholars believe that this educational ill can be cured if teachers critically reflect on their experience. For instance, Ruch (2000) believes that critical reflection transforms practice by challenging existing social, political and cultural conditions. But is this ever possible for powerless teachers in a conformist education system that is not conducive to change?

\section{PURPOSE AND SIGNIFICANCE}

This study aims to discover why language teaching in public high schools in Iran is so shallow, simplistic and disconnected from the glorious rhetoric of the day. To this end the researcher followed a data first mode of research by theorising from the professional life of experienced language teachers willing to share their experience with the researcher.

This work is significant because it gives voice to the oft-silenced group in education system. To this end, the study is conducted "with" not "on" teachers. Theorising from teachers' voice, the study explores why knowledge of the universal principles of language teaching and personal theories generated through reflection are not sufficient to improve practice. While universal principles and teacher-generated knowledge define the whole universe of possible actions, it is a set of context-specific parameters that specify the culturally permissible and legitimate set of actions. That is, there are parameters of language teaching without which principles would be useless. Thus the study is significant because it contributes to the knowledge base for language teacher education by providing some parameters that account for the situated nature of teaching knowledge.

\section{RESEARCH METHODOLOGY}

\section{A. Participants}

Theoretically relevant data was collected through interviews with six experienced language teachers willing to share their experience and views with the researcher. They were all selected from different high schools in Shiraz, a major city located in the eastern parts of the country. All of them were form urban areas. They were all male with more than 12 years of teaching experience. All of them majored in teaching English as a foreign language (TEFL). Two of them had earned their master's degree and the others had earned their bachelor's degree. They were selected on the basis of their teaching experience and their willingness to share their views with the researcher because "understanding requires an openness to experience, a willingness to engage in a dialogue with one that challenges our understandings" (Schwandt, 1999, p. 458). The researcher stopped sampling when theoretical saturation was achieved.

\section{B. Data Collection}

Following Glaser (2001), interviewing was a process of passive listening. Later during theoretical sampling focused questions were used to corroborate emerged concepts and categories. Once categories began to emerge they were used to advance further data collection. When all the emerged categories were fully saturated, data collection terminated and the researcher turns to the task of writing.

In collecting data, the researcher followed the "all is data" dictum (Glaser, 2001). Thus the researcher noted not only what was being told, how it was being told and the conditions of its being told, but also all the data surrounding what was being told. It means whatever was going on was used for conceptualisation, not for accurate description. There is no such thing for grounded theory as bias data or subjective or objective data or misinterpreted data. It is what the researcher is receiving, as a pattern, and as a human being (which is inescapable). It just depends on the research. Data is always as good as far as it goes, and there is always more data.

\section{Data Analysis}

The heart of data analysis in grounded theory is based on three types of coding procedures: open, axial, and selective (Glaser \& Strauss, 1967; Strauss \& Corbin, 1998). Open coding resulted in the umbrella terms "directives and circulars", "teaching teams", "evaluation" and "promotion" as the major mechanisms for creating compliant and uniform behaviour. Axial coding enabled the researcher to relate deskilling (consequence) to disciplined teaching (action), and relate disciplined teaching to its determining conditions (circulars, teaching teams, evaluation, and promotion). Finally selective coding led to the emergence of teaching as a disciplined act as the core category. This conceptualisation had the analytic power to pull together all the pressures that aimed at making teachers' behaviour conform to the top-down directives and circulars.

\section{Trustworthiness}

The researcher's extensive experience as a language teacher for 10 years working under the same conditions as the participants provided him with theoretical sensitivity to sift through the information and identify the prominent categories. Having determined the prominent themes, the researcher reviewed an unmarked transcript, to see if any new concepts or categories emerged, and also to see if the identified categories made sense within the general context of the interview. Thus the building blocks of the theory were developed through the constant comparative techniques, i.e., by altering between understanding and data. They were then confirmed and corroborated through member checking. 


\section{E. Limitations}

Despite the participants' validation of the emerged concepts and categories and the researcher's attempts to triangulate the data against official documents, readers should proceed with caution as they read the findings. Qualitative researchers are the instruments for gathering data, and as human beings, they bring with them their own constructions of the world. However the rigorous analytic schemes of grounded theory helped the researcher ground the findings in the data and avoid personal biases. Despite methodological rigor, however, findings such as these are not a guarantee of truth, for truths are always partial (Clifford, 1986), and knowledge "situated" (Haraway, 1988). We also cannot ignore how interviewer and interviewee negotiate face or manage impressions (Goffman, 1959) in interviews. An interview is but a snapshot in time. Much is left unsaid about events and persons despite the intention of the interviewer to provide a holistic account. Of course, more interviews and stories would deepen our understanding of this exploratory study. Still, the researcher is confident that the categories identified represent a subset of a larger set of macro-structures governing language teachers' work in public high schools in Iran.

\section{Results}

Summary of the theory

Constant comparative technique, theoretical sampling and the analytic schemes of grounded theory yielded teaching as a disciplined act as the core theoretical category. Not only does this conceptualization describes teaching (do as you are told), but also it relates this mode of action to the conditions that bring it about (disciplinary power) and the consequences of accepting this conformist approach (deskilling). First, binding directives and circulars specify a set of permissible actions. These sets of actions are then naturalised as good practice through teaching teams, evaluation scheme, and promotion criteria. These conditions turn teachers into disciplined individuals that do as they are told. Since the externally planned and imposed conditions aim at making language teachers' action predictable and efficient, they are collectively conceptualised as disciplinary power.

Disciplinary power describes the process by which individuals are disciplined to conform their action to an imagined ideal. As Gunzenhauser (2007) states, disciplined selves are complicit in their own subjugation when they comply with the procedures of self-discipline and the comparison of one's traits to social norms. Teachers' shallow and simplistic practice in public high schools in Iran is related to disciplinary power rather than teachers' professional knowledge and skills. By trying to be normal teachers don't use their knowledge and skills and over time lose control of the processes and tasks they felt responsible for as teachers (Kelchtermans, 2005). Hence this approach entails deskilling.

\section{A. Binding Directives and Circulars}

Directives and circulars suppress creativity in teaching and overemphasise convergent teaching by imposing uniform conditions on teachers working under totally varied conditions. When central agencies impose a strong sense of what teachers should be doing, then there is no space for teachers to reflect on their practice to improve it. They see themselves in the consumer end of educational initiatives.

Top-down policies and initiatives inculcate the idea that others' knowledge is superior to teachers' own knowledge. Once they are issued, the principal imposes them on teachers' work. Under such conditions teachers feel excluded in educational decisions. They see their role as following the directives. Instead of being directed by their professional knowledge and experience, teachers' practice is directed by an awareness of the directives and circulars. Omid cogently explains how directives shape his practice:

Directives are license for action, just like the drivers' license. If you are the best driver but you don't have the license you can't drive. On the hand, having drivers' license enables you to drive even though you don't have the potential to drive. Likewise, we cannot teach without enforcing the directives. Following the directives, one can teach without having the practical knowledge of teaching.

Directives have a similar meaning for Ali. He believes that good teaching involves being aware of and understanding the meaning of directives:

We must follow educational directives and circulars issued by the central bureau of education. If we do otherwise, we will be questioned. For the principal of this high school, a good teacher is the one who heeds directives, understands them and implements them.

These comments clearly indicate that teaching is externally controlled. But control is not limited to teaching. Testing is likewise controlled by those outside the education circle. Hamid's comments illuminates teachers' role in testing:

I must test as the testing scheme dictates. Every year a mandated national testing scheme is sent to teachers. It clearly specifies the how and what of testing. Little divergence from the instructions entails being reproached by the colleagues, students, and principal

I follow their initiatives and I am rewarded for acting in tune with their dictates.

\section{B. Teaching Teams}

Within each high school, teachers are allocated to teaching teams of around five to ten people. Teaching teams are appointed a formal leader. Every teaching team holds regular meetings, usually once a month, where work is planned and monitored. Within the teaching team the teachers are involved in each other's teaching. This means that teachers 
can no longer isolate themselves from their colleagues and decide completely individually as to where, when and how teaching will be done.

The organisational division that the teachers are subjected to implies a discipline on the teaching team to which one belongs. It is no longer possible for teachers to cut themselves off and decide themselves how to exercise their profession, as was the case, while it is no longer up to the individual teacher to determine the structure and content of the job, and decisions are instead taken within the teaching team to which one belongs. Hence, adaptability is important. With the head teacher acting in tune with the dictates of the manager, teaching teams are directed towards top-down policies and agendas. Instead of focusing on individual teachers' creativity and initiatives, teachers are all forced into compliance with circulars and directives so that nearly all teachers act and think in the same way. The individual teacher becomes subject to closer scrutiny, primarily by his/her head teacher. Reza's complaints help the reader better grasp how teaching teams and head teachers shape teachers' practice.

In teaching teams the head teacher decides. His decisions are in line with top-down initiatives. The head teacher observes language teachers and approves of teachers who follow the circulars and directives rather than the teachers who follow their own plans of action.

Similarly Omid complains that his teaching is no longer in line with his own professional views. Rather it is the perspectives of the head teacher and his colleague that shape his teaching.

The head teacher has a managerial function rather than an educational one because he reinforces conformity rather than teachers' personal approach. You have to change many times over the years and re-assess your own values. Take up new positions, from different standpoints. And it's important to be able to see how other teachers think in teaching teams. You are judged to be a good teacher to the extent that your teaching complies with that of your colleagues.

\section{Teacher Evaluation}

Teacher evaluation has a control function in that teachers, who know they are being evaluated, are always conscious of the consequences of their actions. They are thus less likely to violate norms designed to sustain the efficiency agenda. The institutional arrangements and evaluation scheme makes even the most able and intellectual of the teachers generally tone down their teaching to the level of the approved acts. Evaluation is dead and deaf to teaching as a professional activity because teachers of all school subjects are evaluated by one and the same scheme. Interviews show that dedicated teachers who try to improve their practice are severely dissatisfied with the evaluation scheme. Rather than measuring teachers' professional knowledge and skills, the scheme measures their conformity with rules and regulations. Ahmad's concise and precise comment on the scope of evaluation scheme better surfaces its hidden agenda.

Teacher evaluation scheme measures factors such as punctuality, clothes, teachers' conduct in the classroom, and observation of norms. Thus rather than motivating teachers to be excellent, it forces them to be normal. The items in the scheme do not measure one's professional expertise. Rather it measures the extent to which one adapts to the right things imposed on teachers from the central office.

When teachers can no longer rely on their professional expertise, then there is a great risk that their professional pride will be eroded. The dilemma of professional pride easily becomes a reality when non-professionals are involved in deciding what good teaching involves. There remains no room for professional pride when non-professionals evaluate teachers with non-professional criteria. Behzad's concerns better elucidates this scenario.

Officials rather than professionals define merit. Even in selecting teachers for beacon schools, head teachers are not consulted.

My evaluation score depends on the principal's subjective idea. To keep my position in the high school, I must do as he wishes.

We don't have any evaluation scheme for language teachers. Teachers of all school subjects are evaluated by the same scheme.

Even the scheme does not differentiate between workers working in factories and teachers. The evaluation scheme was not developed by the ministry of education. It was developed by ministry of labour and social affairs.

Our officials seem to feel that the only way to ensure that good education is going on in individual schools and classrooms is to control teachers' practice through checking their pass rate in the final exams. That is they stick to efficiency agenda by measuring teachers' success by the yardstick of pass rate. Since high pass rate is positively reinforced, teachers are disciplined to reduce the universe of possible pedagogic acts to ones that guarantee high pass rate. Evaluation is a disciplinary mechanism that has normalised high pass rate as the ideal. Omid's comments clearly indicates that the externally imposed yardstick of success it a major factor steering teachers' work.

I am judged by my pass rate rather than my teaching techniques and approach. If students fail, the teacher is reproached. This is not fair. Students may fail for a multitude of unknown reasons. If all my students can communicate but they can't pass the final exam, I will face various punitive measures. Very early in my career I found that I am responsible for students' score rather than their communicative capacity. This awareness helped me to gain the highest pass rate in the past three years.

\section{Teacher Promotion}

According to Dreeben (1970) teachers are salaried employees; they agree, through a written (or unwritten but formal) contract with a school board, on what tasks they shall perform in exchange for pay. That is, circulars and directives 
define a particular set of permissible acts. Promotion is a coherent system of rewarding compliance with the agreed tasks. Teachers are reinforced when they are engaged in the defined acts. One of the subconsciously agreed upon tasks is efficiency in terms of pass rate and final scores. Promotion is a mechanism of reinforcing efficiency. It is extremely unusual and is tied to test scores. To better see how teacher evaluation is contingent upon pass rate, take Reza's comments as exemplary:

The director general gave me the award of advanced skills not for my knowledge but for my pass rate in the final exam. He writes, "We hereby thank you for your ceaseless effort which led to $100 \%$ pass rate in the finals of 2004 . $100 \%$ pass rate is evidence enough to grant you the award of advanced skills. Since I had the highest pass rate in the past few years, they assigned me to the managerial post. Now I am the principal.

Omid corroborates the foregoing comments when he complains that his knowledge and skills in language teaching are not recognized.

Promotion depends on years of experience and pass rate. I am not promoted for my teaching skills and knowledge. I am promoted if I have an acceptable pass rate.

Promotion criteria do the work of normalising and reinforcing a set of non-professional activities. It plays an important part in the creation of disciplined teachers, that is, individuals who conformed to defined activities. Thus a certain mode of thought and action is normalised through promotion criteria. Promotion is the disciplinary technology that allows for a clear and precise measurement of those attributes which power deems important enough to order and manage. In this sense, we can see promotion as an important disciplinary mechanism that creates conformity. Conformity is not the result of overt force that visibly bends the will of those subject to its operation; conformity results from the constant working of invisible constraints that bring us all toward the same normal range of practices and beliefs. To see how promotion criteria normalise a specific set of acts, take Ahmad's comments:

I have to withdraw from my own initiatives and follow the dictates of others. It is only by following the system that I am rewarded.

Every bonuses is for those who follow the system. For instance, teachers of beacon schools are not selected based on their performance in a test, or observation of their teaching skills. They are selected because their approach is in tune with top-down rules and regulations.

Reza also believes that teachers are promoted if they are disciplined, i.e., do as they are told.

Those who have forgotten all principles of language teaching receive a higher salary just because they do what they are told. If you follow your own initiative or if you respond to students' communicative needs, you are marginalized. The reason is that students' communicative ability is not measured in the final exams.

Teachers are aware of the fact that what they do in the classroom is not professionally justified. However, they forsake their professional knowledge and conscience because they are sure that they are promoted only if they do as they are told. Ahmad's points better explains this issue:

I will be promoted if I participate in a set of non-professional activities favoured and specified by the education system. If you participate in cultural activities specified by the directives for four years, you receive one grade. The credit is equivalent to the credit you receive by promoting yourself from BA to MA.

\section{E. Consequence: Deskilling}

Binding circulars together with directed promotion and evaluation delimit practice by impeding the prosecution of strategies and techniques supported by the principles of language learning and teaching and reinforcing conformity with rules and regulation. They discipline teachers to do as they are told. Thus instead of following a reflective approach and developing their practice, they follow a disciplined approach and wait for externally produced plans. Since all planning is done by officials, not teachers, the consequences of this is profound for teachers' professional life. Teachers' complaints are indicative of two destructive consequences.

The first is what we shall call the separation of competence from performance in teaching. Being externally controlled teachers' performance is no longer directed by their competence. When central agencies have a strong and heavily loaded sense of what teachers' should be doing, then there will be little time to consider what teachers themselves think about teaching. In the long run teachers lose sight of the whole process and lose control over their own practice, since someone outside the immediate situation now has greater control over both the planning and what is actually happening. Reza vividly explains how his performance in testing and teaching is detached from his competence in these areas:

Instead of following fundamental concepts of testing English, I develop tests by following the instructions given in the testing scheme. Instead of being directed by principles of language teaching, my teaching approach is shaped by the fixed testing scheme imposed by central agencies. Thus instead of using my knowledge of methodology to respond to learners' needs, I teach to the test by responding to the demands of the scheme.

The second consequence is related, but adds a further debilitating characteristic. This is known as deskilling. As teachers lose control over their own labour, the skills that they have developed over the years atrophy. They are slowly lost, thereby making it even easier for officials to increase control of one's job because the skills of planning and controlling it oneself are no longer available. A general principle emerges here: in one's labour, lack of use leads to loss. To better understand how language teachers in public high schools in Iran lose their knowledge and skills over time, take Omid's points. 
When I entered the profession I was fluent. I have a disempowering exit. I have lost my proficiency because all the way I followed a monolingual approach, i.e., I thought English through Persian. I have become an expert in preparing students for centrally planned tests. I have forgotten the techniques of language teaching because I could never use them. Teaching experience in public high schools deprived me of two precious things: my knowledge of language teaching and my fluency in using English language.

\section{DISCUSSION AND CONCLUSION}

To take structural parameters of practice into account, research approaches moved from the quantitative, positivistic to more narrative-based research that relied on teacher stories as a base of information about teacher knowledge (Carter, 1993). The results of these researches do not lead to the development of generalisations of sample-based findings to population descriptions and explanations that are fundamental to positivistic research, but rather to. . . the framing of patterns with respect to certain themes. Generalisations from this latter form are not laws to which we have to conform to be effective but explanatory propositions with which we can make sense of the dilemmas and problematics of teaching (Carter, 1993, p. 10).

Teaching occurs within a structural context which Cornbleth (1990) argues is the "education system's established roles and relationships, including operating procedures, shared beliefs and norms ... often distinguished as organisation and culture (p.35). Decisions made at all levels throughout the education system, from the central government authority to the school committee, will impact on classroom practice. These decisions may impede or improve practice.

To ensure that decisions made at the top of hierarchy are implemented by those at the bottom of the hierarchy, teachers are exposed to disciplining. According to Foucault (1977) discipline is an effective means of controlling and being able to predict such matters as employee behaviour. The role of discipline is to ensure that many people do their job in a uniform manner and with identical results. To control teachers' behaviour and make it predictable, first permissible acts are issued periodically through circulars and directives. They are then reinforced through teaching teams, evaluation and promotion. That is, they act synergistically to condition teachers to teach in a disciplined manner since some form of uniformity and structure is required for an organisation to function and individuals are thus assumed to be able to renounce certain of their own desires for the good of the collective. Since teachers' actions are directed by forces external to themselves, teaching can be described as a disciplined act.

However, it is characteristic of professional operations that the professionals themselves hold a mandate to decide what the job should consist of, how it is to be done and determine when it has been well done. If teaching is to be professionalised in our high schools, disciplinary power must subordinate teacher power. Only then teachers can challenge forces that systematically de-skill them. They should be trusted to criticise evaluation and promotion criteria from the perspective of their own classroom practices. Professionals must have the autonomy to make decisions that marry skills with knowledge (Goodlad et al, 1990). As Maxcy (1991, p. 160) argued:

Professionalism implies a kind of normative power. Educational professionals ought to have the power to form directives for action with regard to problems arising out of the exercise of their skills and expertise. Teaching professionals ought to have the power to make policy and policy decisions. By professionalism, I have in mind power being placed in the hands of educators such that they may possess leadership in policy and decision making affecting learning in schools (p. 160).

\section{REFERENCES}

[1] Anthony, E. M. (1963). Approach, method and technique. English Language Teaching (17), 63-67.

[2] Brandt, C. (2008). Integrating feedback and reflection in teacher preparation. ELT Journal 62(1), 37-46.

[3] Brookfield, S. D. (1995). Becoming a critically reflective teacher. California: Jossey- Bass.

[4] Carter, K. (1993). The place of story in the study of teaching and teacher education. Educational Researcher, 22(1), 5-12, 18.

[5] Chant, R. H., Heafner, T. L., \& Bennett, K. R. (2004). Connecting personal theorizing and action research in preservice teacher development. Teacher Education Quarterly 31(3), 25-42.

[6] Clifford, J. (1986). Introduction: Partial truths. In J. Clifford \& G. Marcus (Eds.), Writing culture: The politics of ethnography (pp. 1-26). Berkeley: University of California Press.

[7] Cochran-Smith, M., \& Lytle, S. L. (2001). Beyond uncertainty: Taking an inquiry stance on practice. In A. Lieberman, \& L. Miller (Eds.), Teachers caught in the action: Professional development that matters (pp. 167-176). New York: Teachers College Press.

[8] Cornbleth, C. (1990). Reforming curriculum reform. Education Action, 1 (2), 33-43.

[9] Dewey, J. (1933). How we think: A restatement of the relation of reflective thinking to the educative process. Chicago: Henry Regnery.

[10] Dreeben, R. (1970). The nature of teaching: Schools and the work of teachers. Glenview, IL: Scott Foresman.

[11] Glaser, B., \& Strauss, A. (1967). The discovery of grounded theory: Strategies for qualitative research. Chicago: Aldine.

[12] Glaser, B. (2001). The grounded theory perspective: Conceptualisation contrasted with description. Mill Valley, Ca.: Sociology Press.

[13] Goffman, E. (1959). The presentation of self in everyday life. New York: Doubleday Anchor Books.

[14] Goodlad, J., Soder, R., \& Sirotnik, K. (1990). The moral dimensions of teaching. San Francisco: Jossey-Bass. 
[15] Gunzenhauser, M. G. (2007). Resistance as a component of educator professionalism. Philosophical Studies in Education, 38, 23-36.

[16] Haraway, D. (1988). Situated knowledges: The science question in feminism and the privilege of partial perspective. Feminist Studies, 14(3), 575-599.

[17] Kelchtermans, G. (2005). Teachers' emotions in educational reforms: Self-understanding, vulnerable commitment and micropolitical literacy. Teaching and Teacher Education, 21, 995-1006.

[18] Lee, I. (2007). Preparing pre-service English teachers for reflective practice. ELT Journal, 61(4), 321-329.

[19] Maxcy, S. J. (1991). Educational leadership: A critical pragmatic perspective. New York: Bergin \& Garvey.

[20] Richards, J. C. (1991). Reflective teaching in TESOL teacher education. Issues in Language Teacher Education. Anthology series, 30.

[21] Richards, J. C., \& Lockhart, C. (1994). Reflective teaching in second language classroom. New York: Cambridge University Press.

[22] Richards, J. C., \& Rodgers, T. S. (2001). Approaches and methods in language Teaching (2nd ed.). Cambridge: Cambridge University Press.

[23] Ruch, G. (2000). Self and social work: Towards and integrate model of learning. Journal of Social Work Practice, 14(2), 99112.

[24] Schon, D. A. (1983). The reflective practitioner: How professionals think in action.London: Temple smith.

[25] Strauss, A., \& Corbin, J. (1998). Basics of qualitative research: Techniques and procedures for developing grounded theory (2nd ed.). Thousand Oaks, CA: Sage.

[26] Yalden, J. (1987). The communicative syllabus: Evolution, design and implementation. Englewood Cliffs, NJ: Prentice-Hall.

[27] Yip, K. (2006). Self reflection in reflective practice: A note of caution. British Journal of Social Work, 36, 777-788.

Seyyed Ali Ostovar-Namaghi is assistant professor of TEFL at Shahrood University of Technology, Iran. His chief research interest is language teacher knowledge. He has published in a number of leading peer-reviewed journals including: The Reading Matrix (California), Teacher Education Quarterly (California), The Qualitative Report (Florida), The Asian EFL Journal (Korea). Presently he runs courses in EAP at Shahrood University of Technology. 